\title{
Analysis of influence of external atmospheric factors on the accuracy of fault location on overhead power lines
}

\author{
Olga Ahmedova ${ }^{1}$, Anatoliy Soshinov ${ }^{1}$, and Natalia Shevchenko ${ }^{1}$ \\ ${ }^{1}$ Kamyshin Institute of Technology (branch) Volgograd State Technical University, 403874 Russia, Volgograd region, Kamyshin, Lenina \\ st. $6 \mathrm{a}$
}

\begin{abstract}
Devices of fault location are widespread in electrical grids. In overhead power lines of voltages of $10 \mathrm{kV}$ and higher, such devices are based on measurements of parameters in emergency mode. These devices can be divided into two main groups: designed to determine fault location of short circuits and of ground short circuit. In both cases, when detecting fault location, analyzed are not only the current and voltage parameters at the accident time, but also the parameters of overhead power line. When analyzing equivalent circuits of power lines, approximate tabular values of direct and quadrature parameters are used. It was revealed, that the line parameters are significantly affected by external atmospheric factors: ambient temperature, soil moisture, wind strength and direction, ice formation, etc. To accurately determine the fault location, it is necessary to evaluate the influence of these factors on the linear parameters of the overhead line. The paper presents analysis of the influence of changes in atmospheric factors on parameters of overhead power line. A methodology for calculating the operation setpoints of the device for fault location in power line is given.
\end{abstract}

\section{Introduction}

Uninterrupted and reliable transportation of electricity to consumers is one of the main tasks constantly solved by power engineers. To ensure this, electrical grids were created consisting of distribution substations and power lines connecting them.

When insulation of any place in a cable or extended overhead power transmission line (OHL) has a fault, the voltage applied to line creates a leakage or short circuit current through the disturbed section.

The insulation faults can be caused by various factors that either eliminate or continue their destructive influence.

Location of short circuit is especially important, since tripping of permanently faulted line is associated with a shortage of electricity and material damage to consumers. In these cases, accelerated fault search gives a large economic effect.

Devices for fault location (FL) primarily on overhead electrical lines of $10 \mathrm{kV}$ and above, based on measuring emergency conditions, are widely used in electrical grids.

Now there are a wide variety of methods for fault location aroused from a variety of types and nature of faults, as well as structure and operation conditions of electric grids. They can be divided into two large groups: remote and topographic methods [1]. Remote FL methods consist in measuring the distance to the place of fault from the terminal or terminals of line. This group of methods, on one hand, satisfies the requirement on speed of fault location, but on the other hand, it has limited accuracy. Topographic FL methods detect the fault location on path of power transmission line, i.e. topographic location of fault. This group of methods has a high accuracy, but requires a lot of time. The classification of FL methods is presented in Fig. 1.

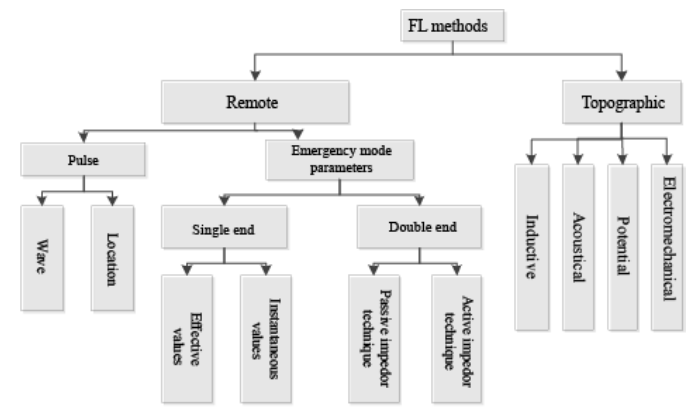

Fig. 1. Classification of FL methods.

To restore the normal operation mode of electric power systems, and reduce damage and costs, it is necessary to quickly and accurately detect the fault location on power lines. The requirements listed above are met by remote fault location methods, subject to increased calculation accuracy. As a rule, the calculation of power transmission line settings is based on shortcircuit currents, which directly depend on the direct and quadrature parameters of the protected power line. Therefore, to ensure the necessary accuracy of calculations, it is necessary to analyze what external

\footnotetext{
* Corresponding author: alexu79@mail.ru
} 
parameters affect the high-voltage power transmission line (HVL).

\section{The method of calculation setpoints of FL device}

Fig. 2 shows a diagram for fault location for a multicircuit overhead power line.

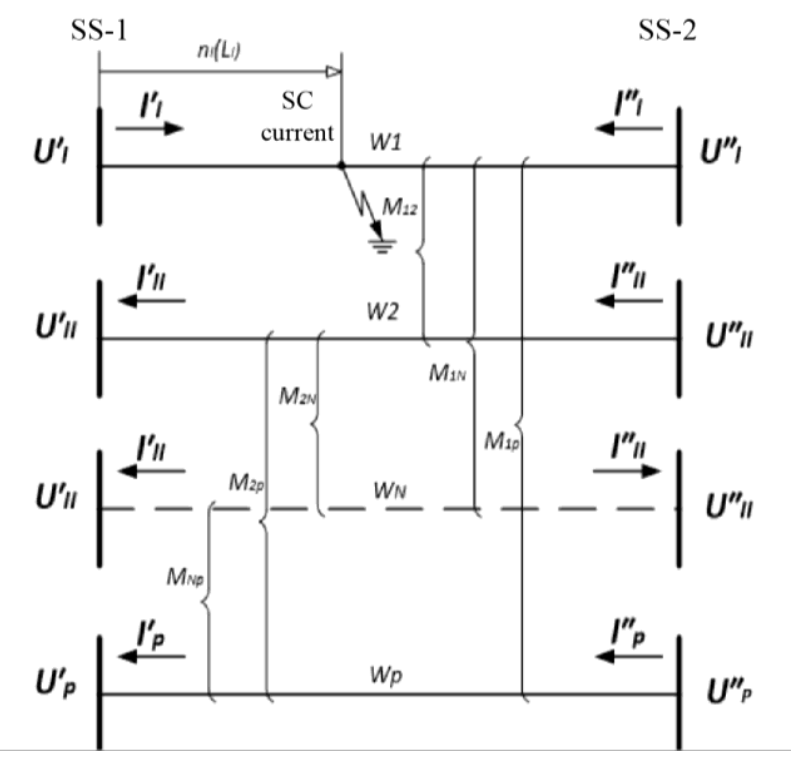

Fig. 2. Multi-circuit PL with mutual induction $\left(\mathrm{n}_{\mathrm{I}}\right.$ is the relative distance from SS-1 to short circuit location $\left(\mathrm{n}_{\mathrm{I}}=\mathrm{L}_{\mathrm{I}} / \mathrm{LOHL}\right)$; $\mathrm{L}_{\mathrm{I}}$ is the absolute distance from SS-1 to short circuit location, $\mathrm{km}$; LOHL is the length of OHL, km).

For the general case of homogeneous overhead lines electromagnetically coupled over the entire path (Fig. 2), the distance to SC location should be calculated [2] by solving a system of $p$ linear algebraic equations (1) with p unknowns:

$$
\left\{\begin{array}{c}
z_{1}\left(I_{I}^{\prime}+I_{I}^{\prime \prime}\right) n_{I}+Z_{12} I_{I I}^{\prime}+\cdots+Z_{1 P} I_{p}^{\prime}=U_{I}^{\prime \prime}-U_{I}^{\prime}+Z_{I} I_{I}^{\prime \prime} \\
z_{21}\left(I_{I}^{\prime}+I_{I}^{\prime \prime}\right) n_{I}+Z_{I I} I_{I I}^{\prime}+\cdots+Z_{2 P} I_{p}^{\prime}=U_{I I}^{\prime \prime}-U_{I I}^{\prime}+Z_{21} I_{I}^{\prime \prime} \\
\cdots \cdots \cdots \cdots \cdots \cdots \cdots \cdots \cdots \cdots \cdots \cdots \cdots \cdots \cdots \cdots \cdots \cdots \cdots \cdots \cdots \cdots \cdots \cdots \cdots \cdots \cdots \cdots \cdots \cdots \cdots \cdots \cdots \cdots \cdots \cdots \cdots \cdots \cdots \cdots \cdots \cdots \cdots \cdots \cdots \cdots \cdots \\
z_{p 1}\left(I_{I}^{\prime}+I_{I}^{\prime \prime}\right) n_{I}+Z_{p 2} I_{I I}^{\prime}+\cdots+Z_{P} I_{p}^{\prime}=U_{p}^{\prime \prime}-U_{p}^{\prime}+Z_{p 1} I_{I}^{\prime \prime},
\end{array}\right.
$$

where $U_{I}^{\prime}, U_{I}^{\prime \prime}, U_{I I}^{\prime}, U_{I I}^{\prime \prime}, \ldots U_{p}^{\prime}, U_{p}^{\prime \prime}$ are the zero sequence voltage measured at the terminals of overhead line $W_{I}$, $W_{P}$;

$I_{I}^{\prime}, I_{I,}^{\prime \prime} I_{I I}^{\prime}, I_{I I}^{\prime \prime}, \ldots I_{p}^{\prime}, I_{p}^{\prime \prime}$ are the zero sequence currents measured at the terminals of the overhead line;

$Z_{I}, Z_{I I}, \ldots Z_{p}$ are the impedances of zero sequence of overhead lines $W_{I}, W_{I I}, \ldots W_{P}$;

$Z_{12}, Z_{21}, \ldots Z 1_{p}, Z p_{1}, Z_{2 p}, Z_{p 2}$ are the mutual induction resistance between the lines $W_{I}-W_{I I}, W_{I I}-W_{I}, \ldots W_{I}-$ $W_{P}, W_{P}-W_{I}, W_{I I}-W_{P}, W_{P}-W_{I I}$.

Distance $\mathrm{n}_{\mathrm{I}}$ for faulted WI OHL should be determined by the expression:

$$
n_{I}=\frac{D_{n I}}{D}
$$

where $D$ is the determinant of the system of equations;
$D_{n I}$ is the determinant obtained from determinant D by replacing a column composed of coefficients with unknown $\mathrm{n}_{\mathrm{I}}$ by a column composed of free terms of the equation.

$$
\begin{aligned}
D & =\left|\begin{array}{cccc}
Z_{I}\left(I_{I}^{\prime}+I_{I}^{\prime \prime}\right) & Z_{12} & \ldots & Z_{1 p} \\
Z_{2 I}\left(I_{I}^{\prime}+I_{I}^{\prime \prime}\right) & Z_{I I} & \ldots & Z_{2 p} \\
\ldots & \ldots & \ldots & \ldots \\
Z_{p 1}\left(I_{I}^{\prime}+I_{I}^{\prime \prime}\right) & Z_{p 2} & \ldots & Z_{p}
\end{array}\right| \\
D_{n I} & =\left|\begin{array}{cccc}
U_{I}^{\prime \prime}-U_{I}^{\prime}+Z_{I} I_{I}^{\prime \prime} & Z_{12} & \ldots & Z_{1 p} \\
U_{I I}^{\prime \prime}-U_{I I}^{\prime}+Z_{21} I_{I}^{\prime \prime} & Z_{I I} & \ldots & Z_{2 p} \\
\ldots & \ldots & \ldots & \ldots \\
U_{p}^{\prime \prime}-U_{p}^{\prime}+Z_{p 1} I_{I}^{\prime \prime} & Z_{p 2} & \ldots & Z_{p}
\end{array}\right|
\end{aligned}
$$

To determine the short circuit location on WI overhead line, currents and voltages at the terminals of the damaged overhead line must be measured, as well as at all overhead lines having an electromagnetic connection with the damaged one.

The calculation formulas for a single-circuit overhead power line (Fig. 3) will take the following form:

$$
l=n l=\frac{U^{\prime \prime}-\underline{U^{\prime}+\underline{Z}_{L} \underline{I}^{\prime \prime}}}{\underline{Z}_{L}\left(I^{\prime}+\underline{I}^{\prime \prime}\right)} L
$$

where $U^{\prime}, U^{\prime \prime}$ and $I^{\prime}, I^{\prime \prime}$ are the voltages and currents at the terminals of the damaged overhead line, respectively; $Z_{L}$ is the impedance of overhead line.

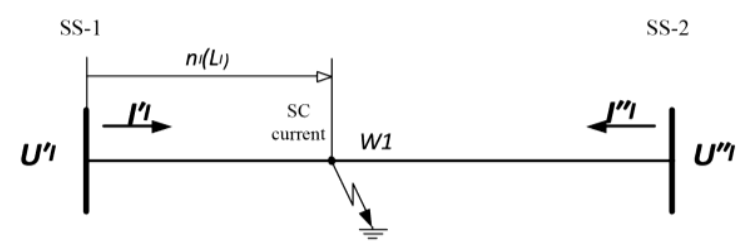

Fig. 3. Single-circuit PL.

The expression (5) shows that in order to accurately detect the OHL fault location, it is necessary to correctly determine the line resistance, take into account external factors that will directly affect it.

Setpoints of starting units (SU) of fault detectors should be calculated:

1) Starting units for symmetrical components of currents $I_{p .0}, I_{p .1}, I_{p .2}$;

2) Starting units for increments of symmetrical components of currents $\Delta I_{p .0}, \Delta I_{p .1}, \Delta I_{p .2}$;

3) Starting units for symmetrical components of currents, operating in conjunction with starting units for

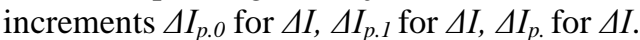

The main condition when choosing setpoints is to ensure the necessary sensitivity during short circuit within the network section where FL function is required. Additional (optional) conditions are elimination of false FL starts in load conditions, as well as minimization the number of unnecessary starts during 
short-circuit on external network elements in which the FL function is not provided.

Regulatory requirements for minimum sensitivity coefficient $k_{s}$ have not been established. It is recommended to take $k_{s}=2$, which ensures reliable startup of FL even with short-circuit, accompanied by significant transition resistance.

Pick-up current of the starting units according to current is determined based on ensuring the required sensitivity coefficient by the expression:

$$
I_{p . n}=\frac{I_{S C \cdot \min n}}{k_{s}}
$$

where $n$ is the sequence number: 1 - direct, 2 - reverse, $0-$ zero; $k_{s}$ is the required sensitivity coefficient; $I_{p}$. is the pick-up current of the starting unit of direct, reverse or zero sequence; $I_{S C \text {.min } n}$. is the minimum value of the corresponding symmetrical component of the primary current at the point of switching on the device during short circuit in rated currents.

Three-phase short circuit current $I_{\mathrm{SC}}$ is calculated using the expression

$$
I_{S C}^{(3)}=\frac{U_{s}}{\sqrt{3} \cdot \sqrt{r_{e}^{2}+x_{e}^{2}}}
$$

where $U_{\mathrm{s}}$ is the system voltage, $\mathrm{V} ; r_{\mathrm{e}}, x_{\mathrm{e}}$ is the active and reactive resistances to the point of short circuit, reduced to the source voltage stage, Ohm.

From the expression (7) it follows that the active and reactive resistances of the overhead line are the variable and effective factors that affect the accuracy of fault location calculations. These parameters are affected by external climatic factors that are not taken into account in calculations.

The line impedance $Z_{\mathrm{L}}$, Ohm, is calculated by the formula:

$$
z_{L}=\left(r_{0}+j x_{0}\right) L_{L}
$$

where $x_{0}$ is the linear inductance of direct sequence, $\mathrm{Ohm} / \mathrm{km} ; r_{0}$ is the linear resistance of direct sequence, $\mathrm{Ohm} / \mathrm{km} ; L_{\mathrm{L}}$ is the line length, $\mathrm{km}$.

As a rule, the linear parameters of power line are considered to be constant values, normalized in the reference literature. The given parameter data are calculated for normal external conditions (ambient temperature $20{ }^{\circ} \mathrm{C}$, sunny, ground resistance under overhead lines is constant, etc.), although under actual conditions of overhead lines operation, climatic conditions vary significantly not only during the calendar year, but also in various climatic zones.

We analyze the influence of a change in atmospheric conditions on the linear parameters of an overhead power line.

Overhead power lines are characterized by the following parameters: specific resistance $R$, specific reactance $X$, specific conductance $G$ and specific susceptance $B$. As a rule, these parameters are taken per unit length of the overhead line and the linear values, R0,
$\mathrm{X} 0, \mathrm{G} 0, \mathrm{~B} 0$, respectively, are used in the calculations. When analyzing power lines, tabular approximate values of direct and quadrature parameters are used in equivalent circuits, although solving problems in unsimplified form leads to significant refinements of known solutions.

\section{Analysis of influence of changes in atmospheric factors on OHL parameters}

\subsection{Analysis of changes in HVL reactance}

Weather factors directly affect the overlap of the OHL insulation, but only visually observed parameters are taken into account, and the effect of changes in soil resistance under HVL is not considered. This parameter is not taken into account in calculations, assuming that the soil has infinite conductivity and all current is concentrated on the surface. In reality, the soil has finite conductivity (Fig. 4) and the current penetrates to a certain depth, depending on the resistance of the soil and taking into account that the soil is homogeneous, decreases with distance from the wire deep into and to both sides.

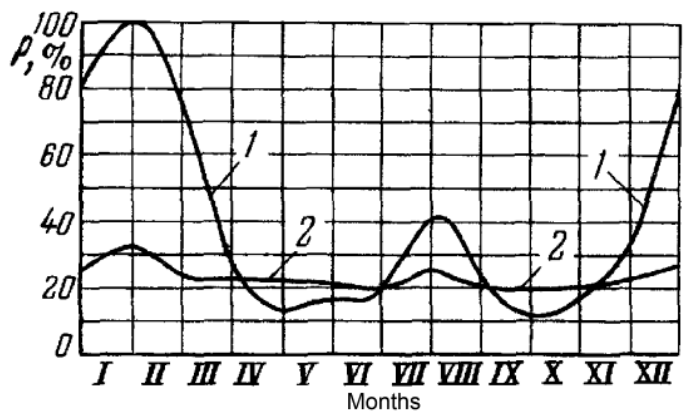

Fig. 4. Change in specific soil resistance over the year. 1 - at a depth of $0.7 \mathrm{~m}$.; 2 - at a depth of $2.5 \mathrm{~m}$.

Analysis of curves presented in Fig. 4, shows that a sharp decrease in soil resistance occurs with an increase in humidity of $15-20 \%$, further humidification has a little effect on its resistance. Tabular resistances are given at a depth of about $0.7 \mathrm{~m}$. However, Fig. 4 shows that in deeper layers of soil it decreases significantly and no longer has pronounced oscillations. This is due to the fact that soil is not subject to seasonal fluctuations (snow melting, overdrying in summer, freezing), but has a constant humidity value, therefore it is assumed that at a depth of $3 \mathrm{~m}$ and deeper the soil resistance will have a value of $15 \%$ of the tabular one [7].

A method for analyzing the effect of the finite conductivity of soil was proposed by Rüdenberg [9].

The wire reactance $X_{w}$ is usually determined by the method of mirror images, i.e. the system "wire - image wire passing underground" is considered with a distance between the wires $D_{z}$ such that the wire resistance of the two-wire line is equal to the wire resistance in the wiresoil system. 


$$
D_{z}=\frac{0.178}{\sqrt{f \gamma \cdot 10^{-9}}} \mathrm{~cm}
$$

where $f$ is the frequency, $\mathrm{Hz} ; \gamma$ is the soil conductance, $\mathrm{S}$.

Reactance of the wire of the wire-soil system is:

$$
X_{w}=29 f \lg \frac{D_{z}}{r_{0}} \cdot 10^{-4} \mathrm{Ohm} / \mathrm{km}
$$

where $r_{0}$ is the wire radius, $\mathrm{m}$.

From expressions (9), (10), it follows that the wire reactance depends on the soil resistance, which varies in a wide range under the influence of factors such as temperature and humidity [8].

Figure 5 shows the relationship between AS-120 wire reactance and the soil resistance.

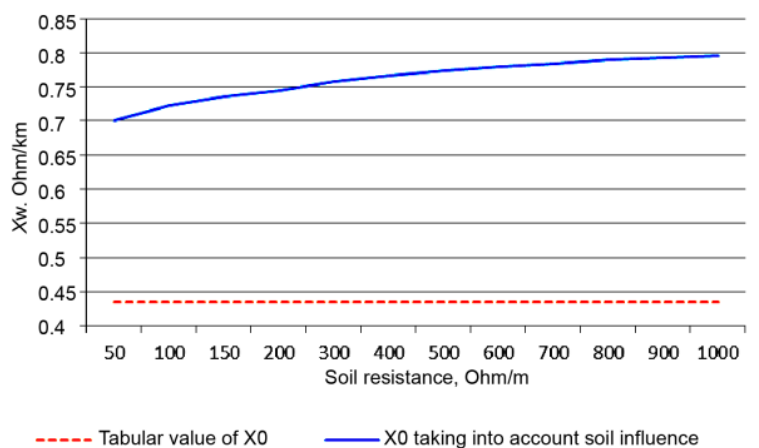

Fig. 5. Relationship between the reactance of $1 \mathrm{~km}$ wire and the soil resistance.

Therefore, if when determining the reactance of the overhead power line wire by the method of mirror images, the final soil conductivity under the overhead line is not taken into account, then the calculation error will be about $65 \%$. The tabular value of reactance does not includes the soil conductivity, therefore it differs from the calculated one taking into account the finite conductivity of soil (10) almost by two times [8].

\subsection{Analysis of the influence of weather conditions on the OHL active resistance}

The data presented in the reference literature is designed for a wire temperature of $20{ }^{\circ} \mathrm{C}$; they do not take into account seasonal changes in ambient temperature inherent for almost the majority of the Russian Federation.

The relationship between resistance and wire temperature is determined by the formula:

$$
R_{0 \mathrm{t}}=R_{020}\left(1+\alpha\left(t_{w}-20^{\circ}\right)\right)
$$

where $R_{020}$ is the tabular value of the specific resistance at wire temperature of $20^{\circ} \mathrm{C} ; \mathrm{t}_{\mathrm{w}}$ is the wire temperature, ${ }^{\circ} \mathrm{C}$; $\alpha$ is the temperature coefficient of electrical resistance, $\mathrm{Ohm} / \mathrm{deg}$.

The temperature of the overhead power line wires depends on the ambient cooling conditions (air temperature) and the current flowing through them. We analyze the relationship between AS-120 wire resistance and temperature $R_{0 t}=f(t)$ in the indicated temperature range (Fig. 6).

The graph shows that increasing the wire temperature by $10^{\circ} \mathrm{C}$ leads to an increase in wire resistance by $4 \%$.

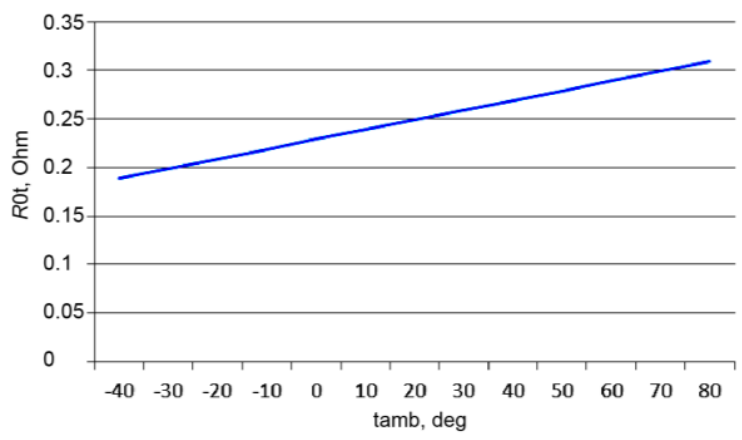

Fig. 6. Relationship between resistance of $1 \mathrm{~km}$ AS-120 wire and ambient temperature.

At current loads, which are limiting in terms of heating conditions, the wire temperature can reach +70 ${ }^{\circ} \mathrm{C}$, and at low ambient temperature and low loads up to $50{ }^{\circ} \mathrm{C}$, therefore, the resistivity can increase by $20 \%$ and decrease by $30 \%$.

From the equilibrium condition, the steady-state wire temperature is determined for any OHL operation mode:

$$
I^{2} R_{020}\left(1+\alpha\left(t_{w}-20^{\circ}\right)\right)=\sigma F\left(t_{w}-t_{\mathrm{amb}}\right)
$$

where $I$ is the wire current, A; $\sigma$ is the heat transfer coefficient equal to the amount of heat removed in $1 \mathrm{~s}$ from $1 \mathrm{~cm}^{2}$ of the wire surface at a temperature difference between the wire and the environment of 1 ${ }^{\circ} \mathrm{C}, \mathrm{W} / \mathrm{m}^{2} \cdot \operatorname{deg} ; F$ is the wire cooling surface, $\mathrm{cm}^{2} ; t_{a m b}$ is the ambient temperature, ${ }^{\circ} \mathrm{C}$.

Heat transfer coefficient:

$$
\sigma=\sigma_{L}+\sigma_{K}=2.8\left(100+0.6\left(T_{w}-273\right)\right) \cdot 10^{-2}+8.95 \sqrt{\frac{p \cdot v}{d}}
$$

where $p$ is the air pressure, $\mathrm{Pa} ; T_{w}$ is the wire temperature, $\mathrm{K}$.

From expressions $(12,13)$ it follows that the wire temperature is influenced not only by wind speed and current passing in line, but also by the ambient temperature.

Given expression (13), we find temperature of the overhead line wire from equation (11):

$$
t_{w}=\frac{I^{2} R_{020}+\sigma F t_{\mathrm{amb}}-20 \sigma F}{\sigma F-I^{2} R_{020} \alpha}+20
$$

Based on expression (14), we construct the relationship between AS-120 wire temperature and the surrounding air temperature, wind speed, and current flowing through it (Fig. 7). Here we take into account atmospheric pressure equal to 1 , and the ambient temperature in the range from $+40^{\circ} \mathrm{C}$ to $-40^{\circ} \mathrm{C}$, wind speed from $0.6 \mathrm{~m} / \mathrm{s}$, corresponding to motion of air masses only by heating up to $6 \mathrm{~m} / \mathrm{s}$. Since $I_{\text {add }}$ is current passing through the overhead line at normal temperature 
$\left(+25{ }^{\circ} \mathrm{C}\right)$ and in the absence of wind, capable of heating the wire to the maximum permissible value $\left(+70{ }^{\circ} \mathrm{C}\right)$, the influence of the current load was estimated in the range from 0 to $I_{\text {add }}$.

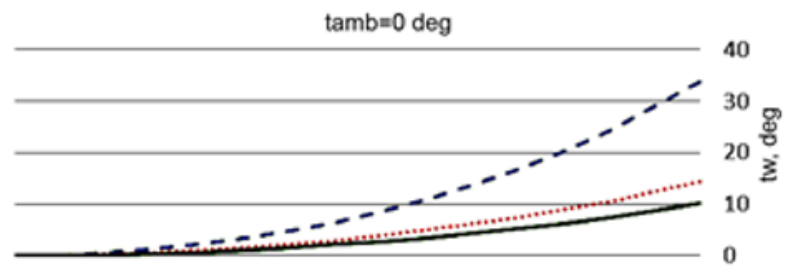

o 255075100125150175200225250275300325350400

I, A

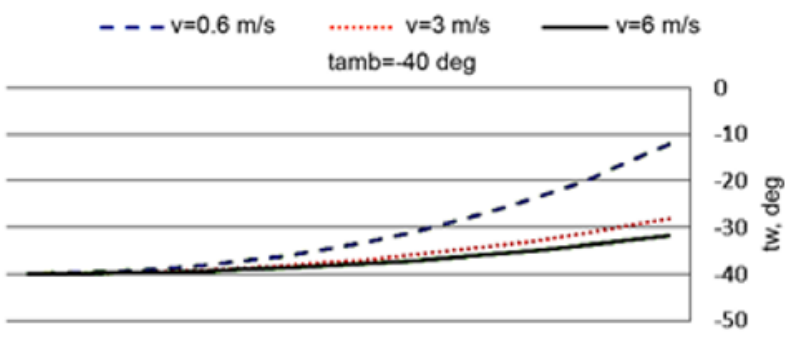

$0 \quad 255075100125150175200225250275300325350400$

\section{I, A}

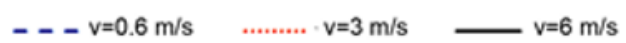

Fig. 7. Relationship between AS-120 wire temperature and the ambient temperature, wind speed, and current flowing through it.

Fig. 7 shows that at small and medium currents, passing through the overhead line and not high wind loads, significant changes in wire temperature occur mainly due to fluctuations in the ambient temperature. If the current load is more than $30 \%$ of the permissible line current and the wind speed is not high, then the current passing through the conductor has a noticeable effect on its heating. With increased wind speed, heat dissipation is significantly improved even for high flowing current.

Determine the wire impedance:

$$
z_{0 w}=\sqrt{R^{2}{ }_{w}+\left(X_{L}-X_{s}\right)^{2}}
$$

Based on expression (15), we plot the relationship between impedance of the AS-240 wire and the ambient temperature, taking into account the final soil conductivity (Fig. 8).

From Fig. 8 it follows that considering the ambient temperature in calculations significantly changes the line impedance. If we estimate the error at two extreme points (at a temperature of $+40{ }^{\circ} \mathrm{C}$ and $-40{ }^{\circ} \mathrm{C}$ ), then it will be $8 \%$ and $23 \%$, respectively. When taking into account the finite conductivity for the same ambient temperatures, the error will be $48 \%$ and $19 \%$.

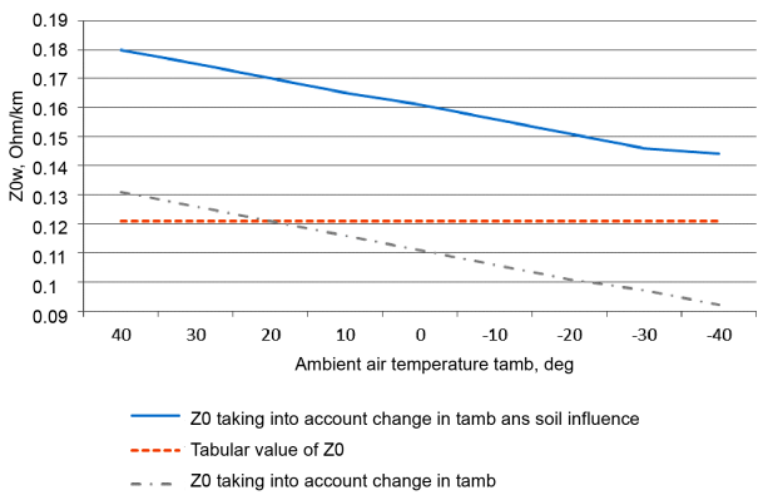

Fig. 8. Relationships between impedance of the AS-240 wire and the ambient temperature, taking into account the finite soil conductivity.

\section{Conclusions}

Based on the performed analysis, the following conclusions can be drawn:

1) The accuracy of fault location on overhead power line directly depends on the consideration of external climatic factors, since their influence cannot be foreseen analytically;

2) An increase in wire temperature by $10{ }^{\circ} \mathrm{C}$ results in an increase in wire resistance by $4 \%$;

3) The tabular value of reactance does not take into account the soil conductivity, therefore it differs from the calculated one, which takes into account the soil finite conductivity by almost two times;

Therefore, fault location devices must be installed on overhead lines with sensors of wire temperature and soil moisture. Information from them at the time of accident will be transmitted to the computer unit, so the fault detection will be performed given the correct data of the power line parameters.

\section{References}

[1] A.I. Eisenfeld, Methods for determining short circuits on overhead power lines using fixing devices (Moscow: Energiya, 2014).

[2] A.I. Eisenfeld, G.M. Shalyt, Detection of places of short circuit on lines with branches, 2nd ed. (Moscow: Energoatomizdat, 1988).

[3] E.A. Arzhannikov, Application of remote principle in the conditions of ground faults for relay protection, automation and devices for fault location on power lines: Thesis for the Dr. tech. sciences (Ivanovo, 1996).

[4] E.A. Arzhannikov, V.Yu. Lukoyanov, M.Sh. Misrikhanov, ed. V.A. Shuina, Location of short circuit on high-voltage power lines (Moscow: Energoatomizdat, 2013).

[5] E.A. Arzhannikov, A.M. Chukhin, Methods and devices for fault location on power lines (Moscow: NTF Energopress, 1998, Biblioteka electromontera, issue 3).

[6] O.O. Akhmedova, Refined algorithm for calculating the active resistance of overhead power line 
taking into account weather conditions, International Journal of Applied and Fundamental Research 12, 3, 387-398 (2016).

[7] O.O. Akhmedova, Analysis of linear parameters of overhead power line taking into account the final conductivity of soil, Successes in modern science and education 4, 4, 130-132 (2017).

[8] O.O. Akhmedova, A.N. Shilin, Study of the influence of ambient conditions on the parameters of overhead power lines for adjusting the settings of relay protection systems in real time, Energy and Resource Saving: Industry and Transport 2, 19, 32-36 (2017).

[9] Ollendorf. Erdstrome. (Berlin, 1928).

[10] Yu.Ya. Lyamets, V.A. Ilyin, N.V. Podshivalin, The software package for analysis of emergency processes and fault location to the power line, Elektrichestvo 12, 2-7 (1996).

[11] A.V. Zakabunin, V.V. Vlezkov, L. Klenovaya, D.A. Abramov, Features of choice of ASKUE depending on the technology of grid construction, Vestnik RGAZU 31, 36, 24 (2019).

[12] V.M. Rastorguev, Power cable monitoring and diagnostics, Vestnik RGAZU 31, 36, 43 (2019).

[13] A.L. Kulikov, M.D. Obalin, Development of software to support decision-making in the elimination of damage on power lines, News of higher educational institutions, Electromechanics 2 (2015).

[14] A.S. Butymov, A.S. Gaivoronsky, A.V. Purtov, A.L. Soloviev, A system for monitoring lightning discharges and fault location on overhead lines, Air lines 3, 37-42 (2012).

[15] A.L. Kulikov, M.D. Obalin, The use of adaptive procedures in algorithms for fault location on power lines, Industrial Energy 12, 35-39 (2013). 